\title{
Heart Rate Recovery Is Impaired in Patients with Psoriasis
}

\author{
Bahadir Sarlia Yasemin Dogan ${ }^{a} \quad$ Ahmet Oguz Baktir $^{\text {a }}$ Hayrettin Saglam $^{a}$ \\ Huseyin Arinc $^{a}$ Serkan Kurtul ${ }^{\mathrm{a}}$ Atıl Avci ${ }^{\mathrm{b}}$ Levent Cinar $^{\mathrm{b}}$ Mahmut Akpek $^{\mathrm{c}}$ \\ Mehmet G. Kayac \\ Departments of a Cardiology and ${ }^{\mathrm{b}}$ Dermatology, Kayseri Education and Research Hospital, and ${ }^{\mathrm{c}}$ Department of \\ Cardiology, Erciyes University School of Medicine, Kayseri, Turkey
}

\section{Key Words}

Psoriasis · Psoriasis area and severity index score $\cdot$ Heart rate recovery index $\cdot$ Cardiovascular risk

\begin{abstract}
Objective: The aim of this study was to investigate the relationship between psoriasis and heart rate recovery (HRR) index. Patients and Methods: A total of 50 patients with a diagnosis of psoriasis and 32 healthy volunteers were included in the study. In all patients, a stress test was performed to calculate the HRR index in a manner which aimed to reach the age-specific maximum heart rate. HRR indices were calculated in all patients and controls. Results: HRR (beats/minute) indices after the 1 st $\left(\mathrm{HRR}_{1}, 26 \pm 10 \mathrm{vs.} 33 \pm 8, \mathrm{p}=0.002\right)$, 2nd ( $44 \pm 11$ vs. $50 \pm 6, p=0.002), 3$ rd ( $51 \pm 7$ vs. $63 \pm 8, p<$ $0.001), 4$ th $(54 \pm 7$ vs. $65 \pm 8, p<0.001)$ and 5 th $(57 \pm 8$ vs. $70 \pm$ $10, p<0.001)$ minutes of the recovery period were significantly lower in the psoriasis group compared to healthy controls. In addition, $\mathrm{HRR}_{1}$ was significantly correlated with duration of psoriasis $(r=0.541, p<0.001)$ and psoriasis area and severity index score $(r=0.511, p<0.001)$. Conclusion: HRR was lower in patients with psoriasis. Given the prognostic value of this test, patients with psoriasis might be at risk for future cardiovascular events and cardiovascular mortality.
\end{abstract}

Copyright $\odot 2013$ S. Karger AG, Basel

\section{KARGER}

E-Mail karger@karger.com www.karger.com/mpp
(C) 2013 S. Karger AG, Basel

1011-7571/13/0226-0567\$38.00/0

This is an Open Access article licensed under the terms of the Creative Commons Attribution-NonCommercial 3.0 Unported license (CC BY-NC) (www.karger.com/OA-license), applicable to the online version of the article only. Distribution permitted for non-commercial purposes only.

\section{Introduction}

Psoriasis is a chronic, relapsing, inflammatory and hypertrophic skin disease which has an unclear etiology. It involves skin surface and joints by affecting the immune system. It is generally characterized by silvery-red skin defects which show a tendency to periodic exacerbation and alleviation [1]. Hypertension, diabetes mellitus, heart failure, coronary artery disease, valvular cardiac disease, peripheral artery disease, hyperlipidemia and cerebrovascular disease are more commonly observed together with psoriasis [2]. Deaths caused by cardiac reasons are increased in patients with psoriasis compared to the general population [3]. It has been thought that autonomic nerve system dysfunction has a role in the etiology and pathogenesis of psoriasis [4].

Heart rate recovery (HRR) is defined as the decrease in heart rate after exercise. Recovery continues until heart rate, blood pressure (BP) and ECG changes return to baseline. HRR is estimated by obtaining heart rates at minutes 1,2, 3 and 5 during the recovery period at maximal heart rate in a patient undergoing a maximal stress test. Abnormal HRR, which is an indicator of abnormal autonomic control, is defined as the inability to achieve a reduction in heart rate by 12 beats or more 1 min after exercise while still standing $[5,6]$. Abnormal HRR has
Bahadir Sarli, MD

Kayseri Education and Research Hospital

Department of Cardiology

TR-38010 Kayseri (Turkey)

E-Maildrsarli@yahoo.com 
been found as an independent predictor of mortality in both men and women $[7,8]$. A correlation has been detected between the amount of reduction in heart rate at first minute of recovery and mortality, where mortality decreases as the amount of reduction increases.

Therefore, in the present study we aimed to evaluate the relationship between psoriasis and HRR index, which is considered to be a cardiovascular risk factor.

\section{Subjects and Methods}

\section{Study Population}

A total of 50 patients (19 male and 31 female; overall mean age $43 \pm 11$ years) with diagnosis of psoriasis presenting to the dermatology outpatient clinic of Kayseri Education and Research Hospital between December 2011 and June 2012 were included in this study. A group of 32 healthy subjects ( 10 male and 22 female; overall mean age $47 \pm 12$ years) were selected as the control group. Diagnosis of psoriasis was made upon clinical presentation with skin lesions. Skin biopsy was required in a limited number of patients $(n=6)$. Psoriasis area and severity index (PASI) was used to determine the severity of psoriasis. The score comprises the three features of psoriasis: psoriatic plaque redness, scaling and thickness, and each were assigned a number from 0 to 4 , with 4 being the worst. Then the extent of involvement of each region of the body was scored from 0 to 6 . The scale of the score ranges from 0 to 72 points, from no psoriasis to maximal disease; higher PASI scores indicate more severe psoriasis. Patients aged $<15$ and $>70$ years, those with history of previous myocardial infarction, ischemic heart disease, $\mathrm{LVEF}<50 \%$, severe valvular failure or stenosis, cardiomyopathy, cardiac arrhythmia, comorbid diseases such as hypertension, diabetes mellitus and chronic renal failure, $\mathrm{Hb}<10$ $\mathrm{g} / \mathrm{dl}$, autonomic system disorder, rheumatoid diseases and patients on methotrexate treatment were excluded from the study.

Baseline ECG was evaluated for all patients with psoriasis and healthy subjects. All participants underwent echocardiography. The 32 healthy volunteers selected as the control group had no organ system or cardiovascular disease on physical, electrocardiographic and echocardiographic examination. In all patients, a stress test was performed to calculate the HRR index in a manner which aimed to reach age-specific maximum heart rate. A stress test was performed according to the Bruce protocol. Maximum heart rate was calculated as follows: maximum heart rate $=220$ - age. Patients who reached $85 \%$ of maximum heart rate were included in the study. The ECG was continuously recorded during the exercise test, at the end of which the heart rate was recorded with the subject at rest in the supine position during a 5 -min post-exercise period. HRR indices were calculated subtracting heart rates at the 1 st $\left(\mathrm{HRR}_{1}\right)$, 2nd $\left(\mathrm{HRR}_{2}\right)$, 3rd $\left(\mathrm{HRR}_{3}\right)$, 4th $\left(\mathrm{HRR}_{4}\right)$ and 5 th $\left(\mathrm{HRR}_{5}\right)$ minutes during the recovery period from the heart rate at peak exercise. $\mathrm{HRR}$ indices were calculated as follows: $\mathrm{HRR}_{1,2,3,4,5}=$ heart rate at peak exercise - heart rate at 1,2,3,4 and 5 min.

\section{Statistical Analysis}

All analyses were carried out using SPSS 15.0 for Windows (SPSS Inc., Chicago, Ill., USA). Continuous variables were given as mean \pm standard deviation; categorical variables were defined as
Table 1. Demographic and clinical features of the patients with psoriasis and controls

\begin{tabular}{lccc}
\hline & $\begin{array}{l}\text { Psoriasis } \\
\text { group } \\
(\mathrm{n}=50)\end{array}$ & $\begin{array}{l}\text { Control } \\
\text { group } \\
(\mathrm{n}=32)\end{array}$ & $\begin{array}{l}\mathrm{p} \\
\text { value }\end{array}$ \\
\hline Age, years & $43 \pm 11$ & $47 \pm 12$ & 0.12 \\
Gender (M/F) & $19 / 31$ & $10 / 22$ & 0.53 \\
BMI, kg/m ${ }^{2}$ & $27.9 \pm 4$ & $28.3 \pm 3$ & 0.61 \\
Ejection fraction, \% & $64 \pm 4$ & $66 \pm 4$ & 0.06 \\
Fasting glucose, mg/dl & $103 \pm 32$ & $93 \pm 8$ & 0.11 \\
Triglyceride, mg/dl & $152 \pm 52$ & $133 \pm 76$ & 0.20 \\
Total cholesterol, mg/dl & $175 \pm 29$ & $178 \pm 30$ & 0.63 \\
LDL cholesterol, mg/dl & $112 \pm 30$ & $97 \pm 37$ & 0.06 \\
HDL cholesterol, mg/dl & $41 \pm 9$ & $39 \pm 6$ & 0.16 \\
Creatinine, mg/dl & $0.9 \pm 0.2$ & $0.9 \pm 0.1$ & 0.98 \\
Duration of psoriasis, years & $14.2 \pm 9$ & & \\
PASI score & $10.8 \pm 10$ & & \\
\hline
\end{tabular}
tein.

$\mathrm{LDL}=$ Low density lipoprotein; HDL = high density lipopro-

percentages. The variables were investigated using the Kolmogorov-Smirnov test to determine whether or not they were normally distributed. Independent samples t test was used to compare continuous variables between the two groups. Nonparametric values were compared with the Mann-Whitney $U$ test. The $\chi^{2}$ test was used to compare categorical data. The Pearson and Spearman correlation coefficient was used to examine the association between the duration of psoriasis and the HRR index. A two-tailed $p$ value $<0.05$ was considered as significant.

\section{Results}

The demographic characteristics of patients with psoriasis and controls are presented in table 1 . The psoriasis group and controls were similar with respect to age, BMI, total cholesterol, high density lipoprotein cholesterol, low density lipoprotein cholesterol, fasting glucose and creatinine levels. There were no significant differences in left ventricular ejection fraction between patients and controls. In patients with psoriasis, mean duration of the disease was $14.2 \pm 9$ years and mean PASI score was $10.8 \pm$ 10 points.

Comparison of the maximal heart rate, maximal systolic and diastolic BP, exercise duration and metabolic equivalents achieved during the exercise stress test between patients with psoriasis and controls are also summarized in table 2. No significant differences were observed in metabolic equivalents $(12.2 \pm 1.58-11.5 \pm 2.3$, 
Table 2. Comparison of exercise test results between patients with psoriasis and controls

\begin{tabular}{lccr}
\hline & $\begin{array}{l}\text { Psoriasis } \\
\text { group } \\
(\mathrm{n}=50)\end{array}$ & $\begin{array}{l}\text { Control } \\
\text { group } \\
(\mathrm{n}=32)\end{array}$ & $\begin{array}{l}\mathrm{p} \\
\text { value }\end{array}$ \\
\hline Duration of exercise, min & $14 \pm 1$ & $13 \pm 2$ & 0.172 \\
Maximum heart rate, beats/min & $169 \pm 8$ & $164 \pm 13$ & 0.029 \\
Maximum systolic BP, mm Hg & $178 \pm 18$ & $174 \pm 23$ & 0.004 \\
Maximum diastolic BP, mm Hg & $86 \pm 3$ & $87 \pm 1$ & 0.612 \\
Maximal metabolic equivalent $_{\text {HRR }}$ & $12 \pm 1$ & $11 \pm 2$ & 0.105 \\
$\mathrm{HRR}_{2}$ & $26 \pm 10$ & $33 \pm 8$ & 0.002 \\
$\mathrm{HRR}_{3}$ & $44 \pm 11$ & $50 \pm 6$ & 0.002 \\
$\mathrm{HRR}_{4}$ & $51 \pm 7$ & $63 \pm 8$ & $<0.001$ \\
$\mathrm{HRR}_{5}$ & $54 \pm 7$ & $65 \pm 8$ & $<0.001$ \\
\hline & $57 \pm 8$ & $70 \pm 10$ & $<0.001$ \\
\hline
\end{tabular}

$\mathrm{p}=0.105)$, maximal heart rate $(164 \pm 11.8-169 \pm 15.2, \mathrm{p}=$ $0.123)$ and diastolic $\mathrm{BP}(86 \pm 3-87 \pm 1, \mathrm{p}=0.612)$ achieved during the exercise stress test between the two groups. However, maximal heart rate $(169 \pm 8-164 \pm 13$, p = 0.029 ) and maximal systolic BP achieved during the exercise test was significantly higher in patients with psoriasis than controls $(178 \pm 18-174 \pm 23, \mathrm{p}=0.004)$.

Results of HRR are presented in table 2. According to these results, $\mathrm{HRR}$ indices after $\mathrm{HRR}_{1}(26 \pm 10$ vs. $33 \pm 8$, $\mathrm{p}=0.002), \mathrm{HRR}_{2}(44 \pm 11$ vs. $50 \pm 6, \mathrm{p}=0.002), \mathrm{HRR}_{3}$ (51 \pm 7 vs. $63 \pm 8, \mathrm{p}<0.001), \mathrm{HRR}_{4}(54 \pm 7$ vs. $65 \pm 8, \mathrm{p}<$ $0.001)$ and $\mathrm{HRR}_{5}(57 \pm 8$ vs. $70 \pm 10, \mathrm{p}<0.001)$ were significantly decreased in the psoriasis group compared to healthy controls. In addition, $\mathrm{HRR}_{1}$ was significantly correlated with duration of psoriasis $(\mathrm{r}=0.541, \mathrm{p}<0.001)$ and PASI score $(\mathrm{r}=0.511, \mathrm{p}<0.001)$.

\section{Discussion}

In the present study, we showed that HRR indices at minute 1,2, 3, 4 and 5 obtained after maximal exercise test were significantly lower in patients with psoriasis than healthy controls. Also, HRR at the first minute of exercise was correlated with the duration of psoriasis and PASI score.

Psoriasis is a chronic inflammatory disease which is characterized by plaques with shiny white desquamation on the skin with a tendency to experience periodic exacerbation and alleviation. The disease affects $1-3 \%$ of different ethnic populations [9] and involves the skin surface and joints by affecting the immune system. In recent years, comorbidities and changes caused by chronic inflammation have been the most compelling aspects of this disease, whose course is characterized by typical clinical findings and histopathological changes.

Atrial fibrillation, stroke and percutaneous coronary intervention are frequently seen in patients with psoriasis and there is an increase in myocardial infarction, cardiovascular mortality and all-cause mortality rates in those with severe psoriasis $[3,10]$. The occurrence of complications, which significantly affect the quality of life and even diminish life span, suggests that psoriasis may be a systemic rather than a skin disease.

Neuroendocrine stress response is mediated by the hypothalamic-pituitary-adrenal (HPA) axis and the autonomic nervous system in the human body. Central effector response is achieved by the corticotropin-releasing hormone system and the locus coeruleus-noradrenergic sympathetic nervous system (brainstem). The brain-skin pathway includes mast cells, nerve growth factor, substance $P$ and the intrafollicular HPA stress pathway, which ensure the corticotropin-releasing hormone, ACTH and cortisol production equivalent to central HPA. When the HPA axis is activated by the hematogenous route, neurosensorial and limbic signaling or the release of primary cytokines such as TNF, IL-1 and IL- 6 to the inflammation site occur [11]. Activated T cells, monocytes and proinflammatory cytokines, most notably TNF- $\alpha$, have all been shown to play pivotal roles in the pathogenesis of psoriasis [12].

It has been emphasized that vaso-occlusive diseases are common in cases with psoriasis and it has been also reported that there is an increase in cardiovascular mortality in these patients [13]. In previous studies, the prevalence of risk factors for coronary artery disease was found to be increased in patients with psoriasis. In particular, it was shown that risk for hypertension and myocardial infarction was increased in patients with severe psoriasis that requires hospitalization $[14,15]$. Presumably due to the effects of inflammation on the HPA axis and the autonomic nervous system, the heart rate and incidence of supraventricular arrhythmias are increased in patients with psoriasis. It has been shown that an autonomic dysfunction occurs; correspondingly, variability in heart rate is decreased $[16,17]$.

Alterations in heart rate during exercise and the recovery period after exercise are determined by the equilibrium between sympathetic and vagal activity. In the recovery period after exercise sympathetic activity, which previously increased during exercise, decreases (as there is an increase in parasympathetic activity), causing a fall 
in heart rate [18]. Abnormal HRR is defined as the inability to achieve a reduction in heart rate by 12 beats or more at minute 1 after exercise while the subject is still standing and has been reported as an independent predictor of cardiovascular mortality in several studies $[8,9]$. Previous studies showed that the HRR index was significantly impaired in patients with various inflammatory diseases, including Behçet's disease, familial Mediterranean fever and systemic lupus erythematosus [19-21]. In subjects with coronary artery disease, HRR is an independent predictor of all causes of mortality regardless of LV function, extent of atherosclerosis in coronary arteries and exercise capacity [22]. Impaired HRR index has been found as an independent predictor of cardiovascular mortality even in healthy subjects [23]. It has also been shown that mortality decreases as the amount of reduction in heart rate increases [24].
Unlike our results, Bulur et al. [25] observed no significant difference in HRR indices between patients with psoriasis compared to healthy controls. However, in that study, the duration of psoriasis and PASI score was lower than in ours. The more severe psoriasis present in our patients might be associated with reduced HRR, indicating more severely deteriorated autonomic functions of the heart.

\section{Conclusion}

HRR is decelerated in patients with psoriasis. Given the prognostic value of this test, patients with psoriasis might be at risk for future cardiovascular events and cardiovascular mortality. Close monitoring of these patients might be beneficial in preventing cardiovascular complications associated with psoriasis.

\section{References}

$>1$ Hsu LN, Armstrong AW: Psoriasis and autoimmune disorders: a review of the literature. J Am Acad Dermatol 2012;67:10761079.

$\checkmark 2$ Friedewald VE, Cather JC, Gelfand JM, et al: AJC editor's consensus: psoriasis and coronary artery disease. Am J Cardiol 2008;102: 1631-1643.

3 Wakkee M, Thio HB, Prens EP, et al: Unfavorable cardiovascular risk profiles in untreated and treated psoriasis patients. Atherosclerosis 2007;190:1-9.

$\checkmark 4$ Pasternak RC, Abrams J, Greenland P, et al: 34th Bethesda Conference: Task Force 1 identification of coronary heart disease risk: is there a detection gap? J Am Coll Cardiol 2003; 411:863-1874.

$\checkmark 5$ Morshedi-Meibodi A, Larson MG, Levy D, et al: Heart rate recovery after treadmill exercise testing and risk of cardiovascular disease events (the Framingham Heart Study). Am J Cardiol 2002;90:848-852.

6 Cole CR, Blackstone EH, Pashkow FJ, et al: Heart-rate recovery immediately after exercise as a predictor of mortality. N Engl J Med 1999;341:1351-1357.

$>7$ Youn HJ, Park CS, Moon KW, et al: Relation between Duke treadmill score and coronary flow reserve using transesophageal Doppler echocardiography in patients with microvascular angina. Int J Cardiol 2005;98:403408.
8 Jagethesan R, Kaufmann PA, Rosen SD, et al: Assessment of the long-term reproducibility of baseline and dobutamine-induced myocardial blood flow in patients with stable coronary artery disease. J Nucl Med 2005;46:212-219.

-9 Christophers E: Comorbidities in psoriasis. Clin Dermatol 2007;25:529-534.

10 Markuszeski L, Bissinger A, Janusz I, et al: Heart rate and arrhythmia in patients with psoriasis vulgaris. Arch Med Res 2007;38:64-69.

-11 Paus R, Theoharides TC, Arck PC: Neuroimmunoendocrine circuitry of the 'brain-skin connection'. Trend Immunol 2006;27:32-39.

-12 Boyman O, Conrad C, Tonel G, et al: The pathogenic role of tissue-resident immune cells in psoriasis. Trends Immunol 2007;28:51-57.

13 McDonald CJ, Calabresi P: Psoriasis and occlusive vascular disease. Br J Dermatol 1978; 99:469-475.

14 Lindegard B: Diseases associated with psoriasis in a general population of 159,200 middleaged, urban, native Swedes. Dermatologica 1986;172:298-304.

15 Mallbris L, Akre O, Granath F, et al: Increased risk for cardiovascular mortality in psoriasis inpatients but not in outpatients. Eur J Epidemiol 2004; 19:225-230.

16 Carvalho M, Soares R, Ribeiro F, et al: Rhythm profile in patients with psoriatic arthritis. Rev Port Cardiol 1990;9:311-317.

17 Novikova DS, Korotaeva TV, Loginova EIu, et al: Clinical implication of assessment of heart rate variability in patients with psoriatic arthritis (in Russian). Ter Arkh 2009;81:47-52.
18 Javorka M, Zila I, Balharek T, Javorka K: Heart rate recovery after exercise: relations to heart rate variability and complexity. Braz J Med Biol Res 2002;35:991-1000.

19 Ardic I, Kaya MG, Yarlioglues M, et al: Assessment of heart rate recovery index in patients with familial Mediterranean fever. Rheumatol Int 2011;31:121-125.

20 Dogdu O, Yarlioglues M, Kaya MG, et al: Deterioration of heart rate recovery index in patients with systemic lupus erythematosus. J Rheumatol 2010;37:2511-2515.

21 Kaya EB, Yorgun H, Akdogan A, et al: Heartrate recovery index is impaired in Behçet's disease. Tex Heart Inst J 2009;36:282-286.

-22 Morshedi-Meibodi A, Larson MG, Levy D, et al: Heart rate recovery after treadmill exercise testing and risk of cardiovascular disease events (the Framingham Heart Study). Am J Cardiol 2002;90:848-852.

23 Cole CR, Blackstone EH, Pashkow FJ, et al: Heart-rate recovery immediately after exercise as a predictor of mortality. N Engl J Med 1999;341:1351-1357.

24 Vivekananthan DP, Blackstone EH, Pothier $\mathrm{CE}$, et al: Heart rate recovery after exercise is a predictor of mortality, independent of the angiographic severity of coronary disease. J Am Coll Cardiol 2003;42:831-838.

25 Bulur S, Turan H, Aslantaş Y, et al: Heart rate recovery index in patients with psoriasis. Turk Kardiyol Dern Ars 2012;40:400-404. 